\title{
DO MULTI-GRIP HANDS INCREASE FUNCTION AND PATIENT SATISFACTION WHEN COMPARED TO TRADITIONAL MYOELECTRIC HANDS?
}

Ivana Popovic ${ }^{1}$, Andrea Cutti ${ }^{2}$, Tiffany Ryan ${ }^{3}$, Michael Schaefer $^{4}$, Erik Andres ${ }^{1}$, Daniela Wuestefeld ${ }^{1}$, Claudia Winkler ${ }^{4}$, Kerstin Baun ${ }^{3}$, Birgit Bischof ${ }^{1}$, Frank Braatz ${ }^{5}$, John Miguelez ${ }^{3}$, Dan Conyers ${ }^{3}$, Andreas Hahn ${ }^{1 *}$

${ }^{1}$ Otto Bock Healthcare Otto Bock, Germany.

${ }^{2}$ Centro Protesi INAI, Italy.

${ }^{3}$ Advanced Arm Dynamics, USA.

${ }^{4}$ Pohlig GmbH, Germany.

${ }^{5}$ Medical University of Gottingen, Germany.

*E-mail: Andreas.Hahn@ottobock.com

\section{INTRODUCTION}

Myoelectric hands progressed from single grip hands (traditional myoelectric devices (TH)) to be multi-grip hands $(\mathrm{MGH})$ which are hypothesized to bring more degrees of freedom, greater range of motion and improved grasping capabilities ${ }^{1,2}$. Their impact on patients' lives has been documented in only a few case studies. The Strategic Consortium for Upper Limb Prosthetic Technologies (SCULPT) aims to assess the potential benefits MGH with respect to function and patient satisfaction compared to $\mathrm{TH}$ systems.

\section{METHODS}

Transradial upper limb amputees currently fitted with Variplus Hand, Sensor Hand Speed, Michelangelo Hand $(\mathrm{MH})$, i-Limb Hand (LH), bebionic Hand (BH), or Vincent Hand $(\mathrm{VH})$ have been enrolled. After informed consent, participants completed a survey either online, during telephone interview, or in person. The survey comprises self-reported outcome measures: (1) Trinity Amputation Prosthesis Experience Scales (TAPES); (2) Disabilities of the Arm, Shoulder, and Hand (DASH); (3) Euro Quality of Life Questionnaire (EQ-5D); and (4) SCULPT questionnaire. The SCULPT questionnaire addresses (a) general assessment, (b) usage of prosthetic hand, (c) prosthetic hand selection, (d) functionality of prosthetic hand, (e) therapy and training, (f) service and failure of the prosthetic hand, and $(\mathrm{g})$ change of the prosthetic hand.

\section{RESULTS}

Data for 124 users were analyzed. Users were mainly male (78\%), median age 38ys (range 18-65ys), $72 \%$ had acquired amputation. $48 \%$ were $\mathrm{TH}$ users, while $52 \%$ were fitted with MGH (27\% MH, 13\% LH, $11 \% \mathrm{BH}, 1 \%$
VH). MGH showed superiority over TH in SCULPT hand selection $(\mathrm{p}<0.001)$ and hand functionality scores $(\mathrm{p}<0.001)$ (Figure 1). MGH were appreciated for their aesthetic appearance, flexible wrist, and functionality of different grip patterns. SCULPT hand selection and hand functionality scores showed weak positive correlations with all TAPES sub-scores $(p<0.01)$. No statistical significant difference was observed in TAPES, DASH, and EQ-5D. Stratification revealed advantages of $\mathrm{MH}$, $\mathrm{BH}$ and TH over LH in DASH core $(\mathrm{p}<0.05)$, TAPES optimal adjustment sub-score $(\mathrm{p}<0.05)$, QALY $(\mathrm{p}<0.01)$ and phantom limb pain (MH vs LH, $\mathrm{p}<0.05$; $\mathrm{BH}$ vs $\mathrm{LH}$, $\mathrm{p}=0.01$, $\mathrm{TH}$ vs $\mathrm{LH} \mathrm{p}<0.01)$. $\mathrm{MH}$ and $\mathrm{BH}$ were worn most with average wearing time of $12 \mathrm{~h} /$ day ( $\mathrm{LH} 8 \mathrm{~h} /$ day, $\mathrm{p}<0.05)$. Users of $\mathrm{BH}$ hand reported highest adjustment to limitation $(\mathrm{p}<0.05)$ and satisfaction $(\mathrm{p}<0.05)$. BH was most appreciated for its appearance $(\mathrm{p}<0.05)$. In comparison to $\mathrm{MH}$ and $\mathrm{TH}$ users gave advantage to $\mathrm{BH}^{\prime} \mathrm{s}$ color and shape.

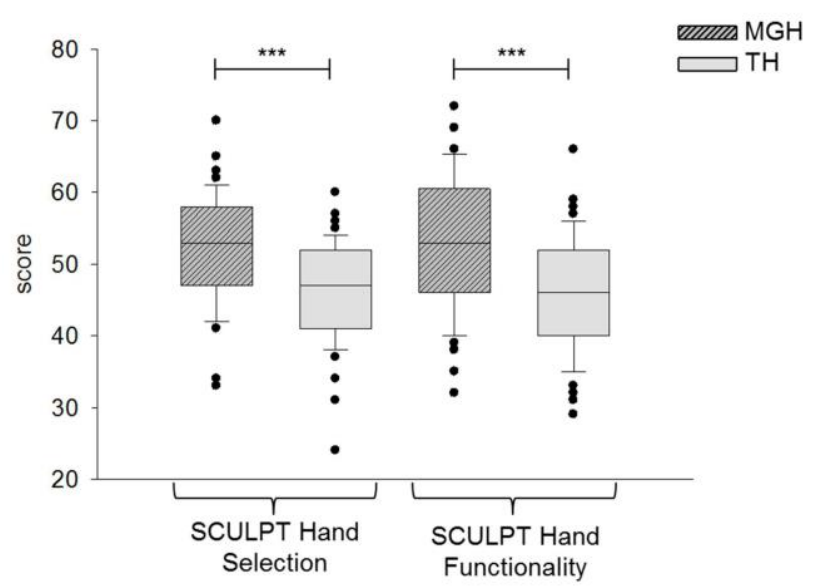

Figure 1. SCULPT hand selection and hand functionality scores for MGH and TH $(* * * \mathrm{p}<0.001)$ 
In everyday life activities $\mathrm{BH}$ and $\mathrm{MH}$ were preferable for hobby activities, $\mathrm{BH}$ for activities such as opening a door, washing, and carrying a bag or briefcase, $\mathrm{MH}$ for doing heavy household chores and cutting activities. Compared to users initially fitted with the MGH and having exclusive experience with $\mathrm{MGH}$, users who experienced both, $\mathrm{TH}$ and $\mathrm{MGH}$, report significantly increased wearing time of their current MGH $(\mathrm{p}<0.05)$, hand functionality (measured via DASH, $\mathrm{p}<0.05$ ), and quality of life (QALY, p<0.05).

\section{CONCLUSION}

Compared to TH, MGH bring additional value to users with respect to aesthetic appearance, flexible wrist options, and functionality of different grip patterns. Still, neither MGH matches a "perfect hand" leaving substantial margin for improvement. Performance based tests as well as cross over studies are suggested to better evaluate the differences between TH and MGH.

\section{SIGNIFICANCE}

One of the largest surveys on exoskeletal myoelectric hand prosthetics allow insights on the relevant differences between single and multi-grip devices.

\section{REFERENCES}

1.Belter JT, et al. Mechanical design and performance specifications of anthropomorphic prosthetic hands: a review. J Rehabil Res Dev. 2013;50(5):599-618 http://dx.doi.org/10.1682/JRRD.2011.10.0188

2.Vergara $\mathrm{M}$ et al. An introductory study of common grasps used by adults during performance of activities of daily living. J Hand Ther. 2014;27(3):225-33. doi: 10.1016/j.jht.2014.04. 002 .

\section{DISCLOSURE}

SCULPT combines the experience of physicians, engineers, therapists, clinicians, and certified prosthetists. SCULPT members are: Advanced Arm Dynamics USA; Centro Protesi INAIL, Italy; Pohlig GmbH, Germany; Otto Bock Healthcare. 